\title{
How Optic Flow and Inertial Cues Improve Motion Perception
}

\author{
Dora E. ANGELAKI \\ Department of Neuroscience, Baylor College of Medicine, Houston, Texas 77030 \\ Correspondence: angelaki@bcm.edu
}

\begin{abstract}
Estimating our egocentric heading direction is an important component of navigation. Recent studies have explored how inertial cues from the vestibular system and optic flow signals from the visual system interact to improve perceptual precision and accuracy. Heading precision is improved through multisensory integration, whereas heading accuracy is maintained through multisensory calibration mechanisms. Neural correlates of these behaviors are found in a large interconnected cortical network, although the specific contributions of each area remain to be explored. Whether and how this multisensory selfmotion cortical circuit contributes to navigation and how egocentric heading signals interact with the allocentric representations for foraging and exploration also remain challenges for the future.
\end{abstract}

Navigation is a fundamental behavior in most animals. During navigation and foraging, information about spatial relationships between environmental landmarks is integrated with self-motion (idiothetic) cues (Mittelstaedt and Mittelstaedt 1980) into a cognitive map of the environment (Stuchlik and Bures 2002). Navigating by selfmotion involves path integration, a process that allows the animal to return fairly directly from any point along its path back to its starting position (Etienne et al. 1986). For example, to navigate from point A to point B using idiothetic cues, multisensory signals must encode three distinct components of self-motion (Fig. 1): the linear speed, the angular speed, and egocentric heading direction. During movement between $\mathrm{A}$ and $\mathrm{B}$, these egocentric signals allow path integration processes to update spatial information about current allocentric head direction and location. While using path integration to navigate, a subject must align their idiothetic sense of position by referencing their location relative to known stable landmarks, which may be either substrate-based local cues or more distant orientation beacons.

Identifying the sensory origins of the signals contributing to spatial orientation and navigation has long posed a challenge for researchers due to the multisensory contributions of motor, vestibular, visual, proprioceptive, and other cues that are difficult to isolate. The field of rodent navigation has focused on investigating how linear and angular speed are used to convert self-motion cues into allocentric head direction, place, and grid signals (for recent reviews, see Knierim and Zhang 2012; Hartley et al. 2013; Moser et al. 2013; Barry and Burgess 2014; Geva-Sagiv et al. 2015). In contrast, the neural basis of egocentric heading direction has been primarily investigated in macaques. This review provides a summary of what is currently known about how visual and vestibular cues influence and control our perceived egocentric heading direction (see also Britten 2008; Angelaki et al. 2009,
2011; Fetsch et al. 2010, 2011; DeAngelis and Angelaki 2012).

\section{MULTISENSORY CUES FOR HEADING PERCEPTION}

Patterns of image motion across the retina ("optic flow") can be strong cues of self-motion, as evidenced by the fact that optic flow alone can elicit the illusion of self-motion (Mach 1875). Multiple studies have since characterized the behavioral observation that large-field optic flow stimulation induces self-motion perception (Brandt et al. 1972; Berthoz et al. 1975; Dichgans and Brandt 1978). In parallel, many visual psychophysical and theoretical studies have shown that optic flow also provides powerful cues of heading direction (Gibson 1950) and have examined how heading can be computed from optic flow (for review, see Warren 2003). During translation, the resulting retinal pattern consists of a radial flow field from which the point of zero velocity can be used to estimate heading (Tanaka et al. 1986; Warren et al. 1988; Duffy and Wurtz 1995; Britten 2008). However, retinal image motion is often confounded by eye/head and object movement, such that heading perception can often be ambiguous. Thus, visual cues alone might not always be appropriate for accurate heading estimation.

Independent information about the motion of our head/body in space can arise from the vestibular system (Angelaki and Cullen 2008). Psychophysical studies of heading discrimination using two-alternative forcedchoice tasks have reported vestibular heading discrimination thresholds in darkness that are as small as a few degrees (Gu et al. 2007; Fetsch et al. 2009; Butler et al. 2010, 2015; de Winkel et al. 2010; Drugowitsch et al. 2014). Such threshold values are comparable (although larger) with those described in visual heading discrimi- 


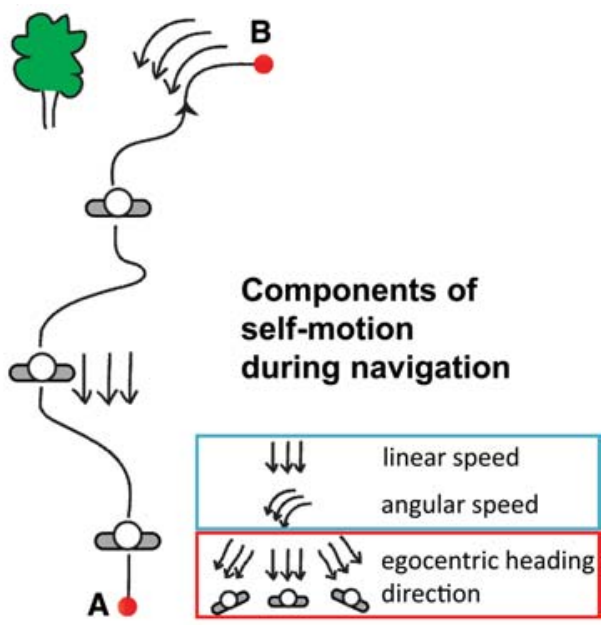

Figure 1. Schematic illustrating the three components of selfmotion cues important for spatial navigation. This review focuses specifically on egocentric heading direction.

nation tasks (Warren and Hannon 1990; Royden et al. 1992; van den Berg and Brenner 1994; Stone and Perrone 1997). Heading thresholds in darkness increase by more than 10-fold after bilateral labyrinthectomy, suggesting that vestibular cues are critical for heading discrimination during inertial motion ( $\mathrm{Gu}$ et al. 2007).

Thus, both visual and vestibular cues work together to estimate heading, and many recent studies have investigated both the perceptual benefits of multisensory integration and the neural correlates of these interactions. Next, we summarize the established properties of multisensory heading perception by first defining the concepts of precision and accuracy.

\section{DEFINITION OF PRECISION AND ACCURACY}

When throwing darts (Fig. 2A), we want to be both accurate (unbiased, darts centered on target) and precise (low variability of hit distribution). A skilled observer would hit the center bullseye each time; thus, dart-throwing performance would be accurate (Fig. 2A, left panels). Alternatively, the observer may always miss the bullseye and consistently throw darts at a different location, resulting in low accuracy in hitting the bullseye (Fig. 2A, right panels). On the other hand, the performance of an experienced observer would also show low variability (Fig. $2 \mathrm{~A}$, top panels), whereas the behavior of a novice observer may exhibit high variability (Fig. 2A, bottom panels). Thus, in Figure 2A, a small bias indicates high accuracy, whereas a low variability indicates high precision. Accuracy, represented by the bias, and precision, represented by the variability, together characterize the quality of motor performance.

Similarly, proficiency of sensory perception can be assessed by two independent and complementary properties: Precision is the sensitivity or threshold (also referred to as "reliability," computed as the "sigma" of a cumulative Gaussian fit of a psychometric function; Fig. $2 \mathrm{C}, \mathrm{D})$, whereas accuracy is the bias of the percept in relation to the actual stimulus (mean of psychometric function; Fig. 2D). An ideal percept is both precise (minimum threshold) and accurate (unbiased), although the two properties are independent, such that some precise cues could also be inaccurate (Fig. 2D).

\section{MULTISENSORY INTEGRATION IMPROVES PERCEPTUAL PRECISION}

Numerous studies have demonstrated that multisensory integration increases the precision of perceptual performance (e.g., Ernst and Banks 2002; Alais and Burr 2004; Knill and Pouget 2004). In particular, as illustrated by the psychometric functions in Figure 2C, the precision of perception in a heading discrimination task (Fig. 2B) increases when both vestibular (i.e., inertial) and visual (i.e., optic flow) signals indicate self-motion as compared with when either cue is present alone (Gu et al. 2008; Fetsch et al. 2009, 2011, 2013; Butler et al. 2010, 2015; de Winkel et al. 2013).
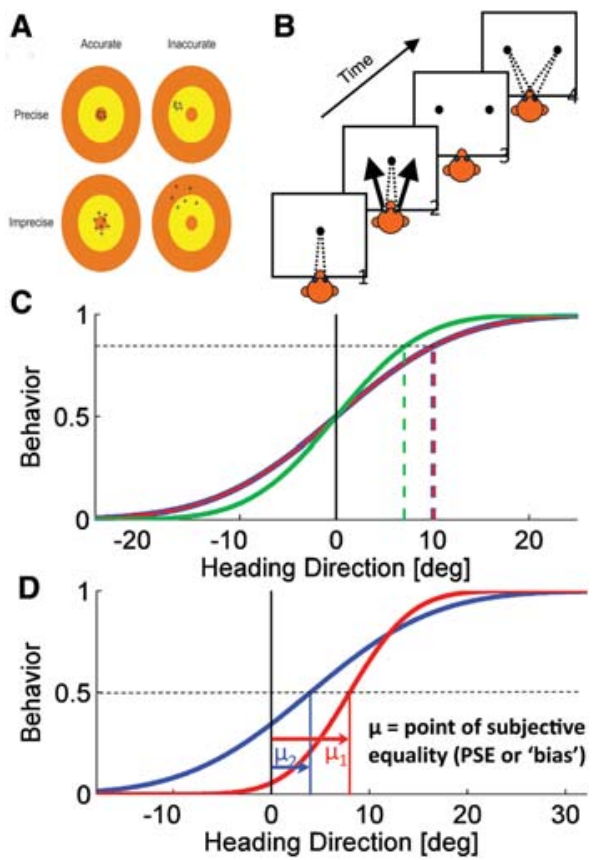

Figure 2. Schematics of how multisensory cue integration and calibration control precision and accuracy. (A) Definition of precision and accuracy using the example of darts. $(B)$ Heading discrimination task. $(C, D)$ Definition of precision and accuracy in psychometric functions. Precision is the sensitivity or threshold (also called "reliability," computed as the "sigma" of the cumulative Gaussian fit of a psychometric function) ( $C$, vertical dashed lines). Accuracy is the bias of the percept in relation to the actual stimulus (mean of cumulative Gaussian fit of psychometric function; $\mu$ in $D$ ). An ideal percept is both reliable (minimum threshold) and accurate (unbiased), although some reliable cues might be inaccurate $(D)$. In this case, the combined estimate would also be inaccurate according to Equation 2. Red/ blue, single-cue psychometric functions. Green, combined cue psychometric function. 
Statistically optimal cue integration predicts that threshold in the combined condition $\sigma_{\text {com }}$ can be calculated from the single-cue vestibular and visual thresholds according to the equation

$$
\sigma_{\mathrm{com}}=\sqrt{\frac{\sigma_{\mathrm{vest}}^{2} \sigma_{\mathrm{vis}}^{2}}{\sigma_{\mathrm{vest}}^{2}+\sigma_{\mathrm{vis}}^{2}}} .
$$

This is because an optimal estimator (in terms of minimizing the variance of the final estimate) should combine sensory information using a rule that weights the single-cue estimates in proportion to their reliability, or the inverse of their variance (Knill and Saunders 2003; Hillis et al. 2004):

$$
\begin{aligned}
& \hat{S}_{\mathrm{com}}=w_{\text {vest }} \hat{S}_{\mathrm{vest}}+w_{\mathrm{vis}} \hat{S}_{\mathrm{vis}}, \\
& w_{\mathrm{vest}}=\left(1 / \sigma_{\mathrm{vest}}^{2}\right) /\left(1 / \sigma_{\mathrm{vest}}^{2}+1 / \sigma_{\mathrm{vis}}^{2}\right), \\
& w_{\text {vis }}=\left(1 / \sigma_{\mathrm{vis}}^{2}\right) /\left(1 / \sigma_{\text {vest }}^{2}+1 / \sigma_{\mathrm{vis}}^{2}\right) .
\end{aligned}
$$

As a result, more precise cues should have a higher weighting and less precise cues should have a lower weighting in the combined estimate. Indeed, empirically measured heading discrimination thresholds during combined vestibular-visual heading perception were close to the predictions produced by a statistically optimal cue combination rule (Gu et al. 2008; Fetsch et al. 2009, 2011, 2013; Butler et al. 2010, 2015; de Winkel et al. 2013).

\section{MULTISENSORY CALIBRATION IMPROVES PERCEPTUAL ACCURACY}

Whereas many studies have shown that multisensory cue integration can lead to a small improvement in precision (according to Eq. 1), it is important to appreciate that multisensory integration can lead to compromised accuracy, if the most reliable cue is inaccurate. Because of the combination rule for cue-weighting (Eq. 2 ), the combined estimate would lie close to the most reliable cue, regardless of whether or not that cue is accurate-often compromising the accuracy of the combined perception.

Such a solution would be problematic for everyday life, unless robust calibration mechanisms existed to maintain long-term accuracy. Robust plasticity mechanisms maintain the accuracy of sensory perception during development (Gori et al. 2008, 2010; Nardini et al. 2008; Stein and Rowland 2011) and in adulthood (Burge et al. 2010; Ernst and Di Luca 2011; Zaidel et al. 2011, 2013). In fact, there is growing evidence that the ability to optimally integrate cues (in the form of improved thresholds) develops late in adolescence (Gori et al. 2008; Nardini et al. 2008). It is thought that the reason for this developmental delay is that maintaining perceptual accuracy through calibration is more important and more fundamental than the small increase $(\leq \sqrt{ } 2)$ in precision brought about through multisensory integration (Eqs. 1, 2). Thus, until robust calibration mechanisms are set in place during development to ensure perceptual accuracy, optimal integration, in the form of threshold improvement, does not occur (Gori et al. 2010, 2011a,b, 2012a,b,c).

Given the demonstrated importance of maintaining accuracy (through multisensory calibration) versus improving precision (through multisensory integration) during development, it is logical to assume that the brain maintains the ability to calibrate our senses relative to each other and relative to the environment, even in adulthood. Indeed, recent macaque and human psychophysics experiments have revealed the existence of two adult calibration mechanisms (Zaidel et al. 2011, 2013): In the absence of external feedback, an implicit, "unsupervised," calibration mechanism acts alone to reduce or eliminate a discrepancy between the cues by shifting single-cue percepts toward each other (Zaidel et al. 2011). In the presence of external feedback, which provides information regarding cue accuracy, the unsupervised mechanism works in parallel with a second "supervised" calibration mechanism, which relies only on the combined (multisensory) estimate. The goal of the unsupervised calibration is "internal consistency" and is achieved by simultaneously comparing the cues with one another and calibrating them individually. In contrast, the goal of the supervised calibration is "external accuracy" and is achieved by comparing the combined cue estimate with feedback from the environment (Zaidel et al. 2013). Although unsupervised calibration is more implicit and thus likely to represent a perceptual shift, the supervised component seems to use a more explicit mechanism, possibly targeting the mapping between perception and action. In combination, these two calibration mechanisms can ultimately achieve both internal consistency and external accuracy. A similar distinction between implicit and explicit components is found in studies of sensorimotor plasticity (Mazzoni and Krakauer 2006; Simani et al. 2007; Haith et al. 2008; Taylor and Ivry 2011).

\section{BIASES IN HEADING PERCEPTION IN THE PRESENCE OF MOVING OBJECTS}

The behavioral studies summarized above have examined heading perception in a rigid environment comprising only world-stationary objects. However, this is not an accurate representation of our natural surroundings as the world around us comprises both world-stationary objects and independently moving objects. For effective navigation in such a complex environment, we should be able to accurately judge our heading direction robustly. However, object motion is known to induce biases and reduce the accuracy of heading perception in the visual system (Warren and Saunders 1995; Saunders and Warren 1996). The movement of objects through space disrupts the pattern of optic flow due to the motion of the observer, making it difficult to distinguish between self-motion and object motion (Warren and Saunders 1995; Royden and Hildreth 1996).

Most previous studies that considered nonstationary environments have examined the influence of object mo- 

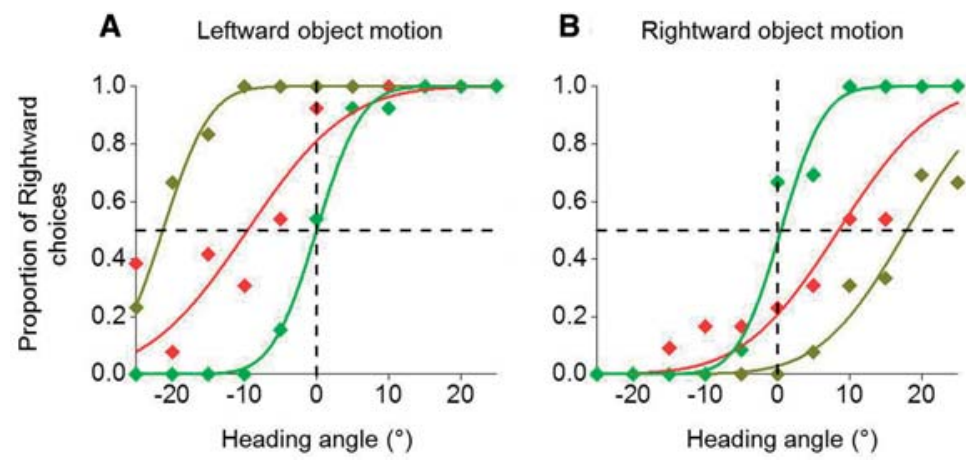

Figure 3. Heading perception in the presence of moving object. $(A, B)$ Example psychometric functions from a monkey in the presence of an object moving leftward $(A)$ or rightward $(B)$. Heading perception is heavily biased in vestibular (dark yellow) and visual (red) single cue, but not combined (green), conditions.

tion only when self-motion was specified exclusively by visual signals (i.e., optic flow simulating observer movement in the world). In contrast, self-motion is usually always accompanied by inertial motion wherein vestibular signals provide independent information about head/ body movement in space. It is thus plausible that vestibular signals would play a role in improving perceptual performance when visual signals alone cannot resolve this perceptual ambiguity completely. Indeed, recent studies have shown that vestibular signals play an important role in allocentric judgments of object trajectory in moving observers (Fajen and Matthis 2013; Dokka et al. 2015). We therefore hypothesized that the addition of vestibular cues to optic flow would improve the accuracy of heading perception in the presence of independently moving objects.

As illustrated in Figure 3, combined visual and vestibular heading stimuli improve the accuracy of heading discrimination in a nonrigid environment containing a large, independently moving object. A rhesus monkey was trained to perform a heading discrimination task with vestibular, visual, and combined vestibular-visual headings in both the absence and presence of an independently moving object. Remarkably, a moving object significantly reduced the accuracy of heading discrimination (i.e., there were large biases in perceived heading that depended on the direction of object motion) when selfmotion was specified by visual or vestibular cues individually (Fig. 3, red or dark yellow). Importantly, the accuracy of heading discrimination improved significantly in the presence of multisensory vestibular-visual signals (Fig. 3, green).

\section{BIASES IN HEADING PERCEPTION IN THE PRESENCE OF EYE AND HEAD MOVEMENTS}

But it is not only moving objects that cause biases in heading perception. In addition, eye-in-head, head-inbody, and body-in-world rotations alter the optic flow patterns encoded in the retina, such that strong perceptual biases can result (Royden et al. 1992, 1994; Crowell et al. 1998). Although psychophysical studies have provided evidence that visual cues may play a role in reducing perceptual biases and accurately estimating heading direction in the presence of rotations (Grigo and Lappe 1999; Li and Warren 2000, 2002, 2004; Crowell and Andersen 2001; Royden et al. 2006), significant perceptual biases persist (Royden et al. 1992; Royden 1994; Banks et al. 1996). It has been well established that motor-related movement information from extra-retinal efference copy signals help reduce these biases (for a recent literature review, see Sunkara et al. 2015). Whether the multisensory influence of vestibular cues also reduces rotation-induced biases in heading perception is possible, but has not yet been tested.

\section{NEURAL CORRELATES OF MULTISENSORY HEADING PERCEPTION}

In recent years, the neural correlates of multisensory heading perception have also been systematically explored. Figure 4A summarizes a cortical circuit including areas with neurons tuned to both optic flow and inertial heading cues (varying shades of red and dark yellow, respectively). Based on these findings, heading perception likely involves several multisensory cortical regions, such as the dorsal medial superior temporal (MSTd) area (Bremmer et al. 1997; Duffy 1998; Page and Duffy 2003; $\mathrm{Gu}$ et al. 2006; Maciokas and Britten 2010), the ventral intraparietal (VIP) area (Bremmer et al. 1999, 2002; Schlack et al. 2002; Zhang et al. 2004; Maciokas and Britten 2010; Chen et al. 2011a,b, 2013a,b), the visual posterior sylvian (VPS) area (Chen et al. 2011c), and the pursuit area of the frontal eye fields (FEF; Y Gu, GC DeAngelis, DE Angelaki, unpubl.).

Whereas MSTd, VIP, VPS, and FEF are all examples of cortical areas shown to process both optic flow and vestibular heading, other cortical areas, such as the parietoinsular vestibular cortex (PIVC), are tuned to vestibular heading cues only (Chen et al. 2010). Furthermore, other cortical areas, such as the medial temporal area (MT) (Chowdhury et al. 2009) and visual area V6 (R Fan, GC DeAngelis, DE Angelaki, unpubl.), are tuned only to optic flow.

Figure 4B summarizes the mean heading tuning strength of each area, using a direction discrimination in- 
A

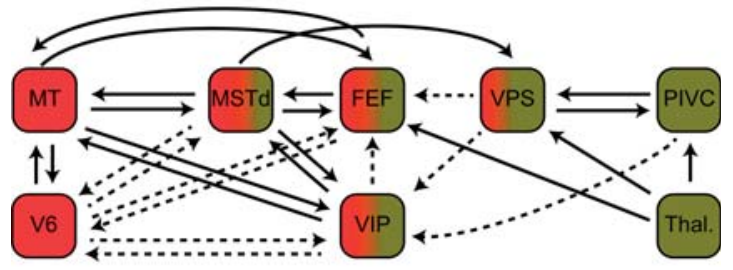

Weak Vestibular DDI

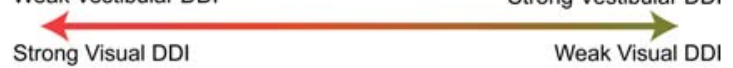

B

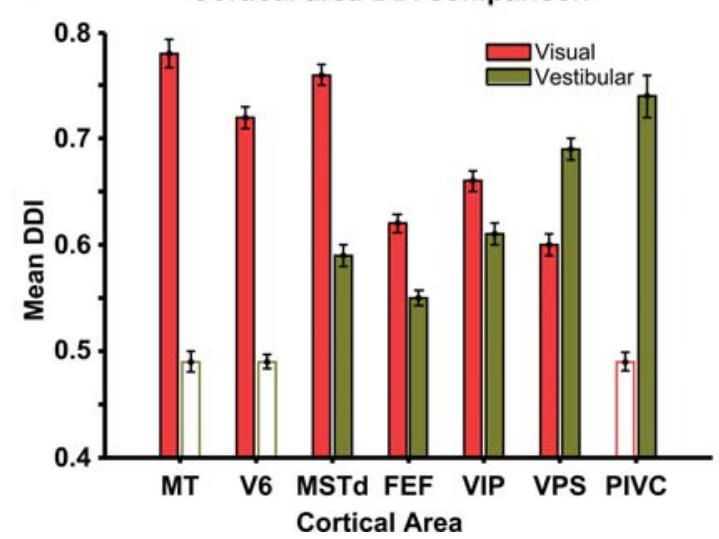

Figure 4. Cortical network of visual/vestibular heading areas. (A) Schematic of area connectivity, with each area color-coded according to visual/vestibular tuning strength. (B) Distributions of mean visual (red) and vestibular (green) DDI (Direction Discrimination Index) \pm SE across cortical areas. Open bars are used for areas without significant tuning. dex (DDI), which takes on values between 0 (no tuning) and 1 (strong tuning). Because the same experimental protocols and analyses were used to measure how well all areas are tuned to heading, the mean $\mathrm{DDI}_{\mathrm{vis}}$ and mean $\mathrm{DDI}_{\text {vest }}$ values are directly comparable (Fig. 4B). Of particular note is the fact that there appears to be a progression of tuning strength to visual and vestibular cues across the four multisensory areas, MSTd, VIP, FEF, and VPS.

Of these multisensory areas, MSTd and VIP have been studied the most. Although some differences in response properties between VIP and MSTd have been noted (e.g., Chen et al. 2011a; Yang et al. 2011), MSTd and VIP share many similarities in their tuning to visual and vestibular stimuli and also show strong correlations between neural activity and perceptual choice (Gu et al. 2008; Maciokas and Britten 2010; Chen et al. 2011a,b, 2013a,b,c). As illustrated in Figure 5, where firing rate is plotted as a function of heading direction for the vestibular (dark yellow) and visual (red) conditions, multisensory MSTd/ VIP cells fall into one of two groups, which were identified by constructing spatial tuning curves as heading direction was varied: (1) "Congruent" neurons had similar visual/vestibular preferred stimuli and thus signaled the same heading direction under both single-cue stimulus conditions. For example, the congruent MSTd cell preferred leftward (negative) headings for both stimuli (note that heading directions are referenced to either the real or simulated self-motion; thus, similar tuning in the visual and vestibular conditions defines a congruent cell). In contrast, the congruent VIP cell example preferred rightward (positive) heading directions. (2) "Opposite" neurons preferred opposite directions of heading under the visual and vestibular stimulus conditions, as shown with the MSTd and VIP examples in Figure 5. The extent of
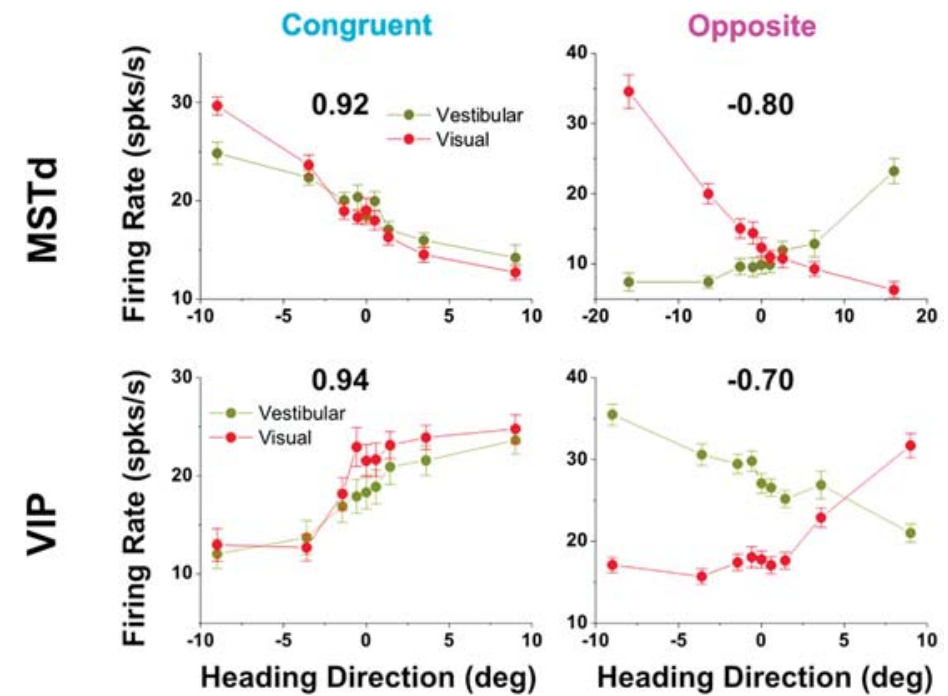

Figure 5. Two types of multisensory neurons in MSTd (top) and VIP (bottom). Heading tuning curves, for example, congruent and opposite cells (dark yellow: vestibular; red: visual). $0^{\circ}$ heading denotes straight forward translation, whereas positive/negative numbers indicate rightward/leftward directions, respectively. Data (from Gu et al. 2008 and Chen et al. 2013a) illustrate firing rate means and SE. The numbers on each panel illustrate the "Congruency Index" for each cell. 
A
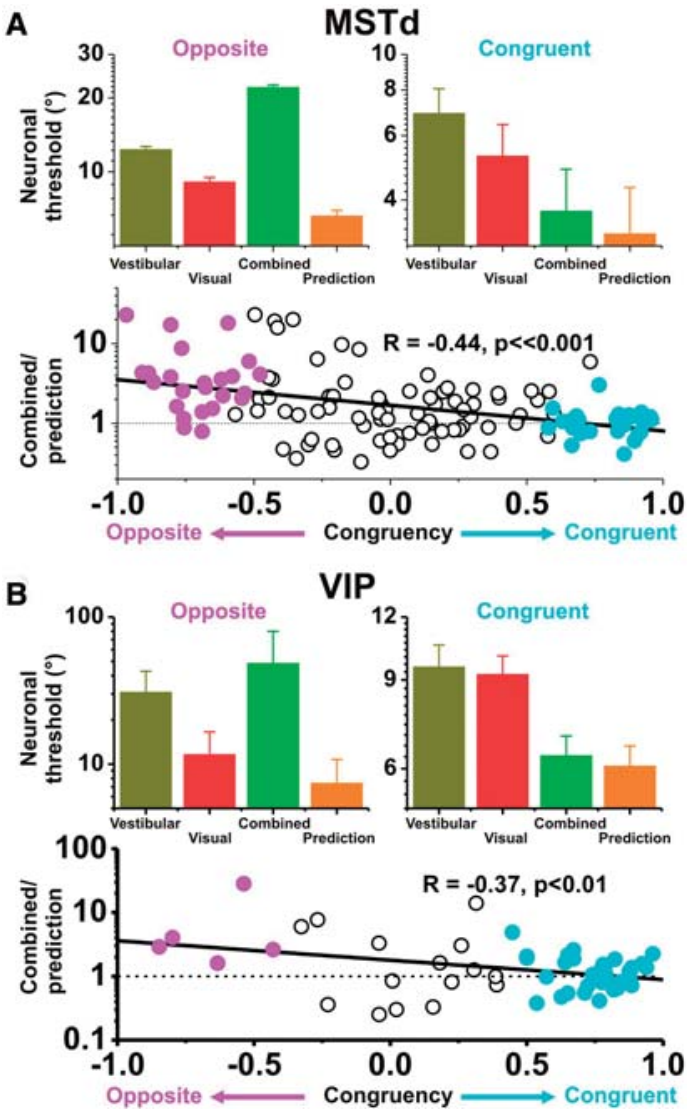

Figure 6. Improvement in neuronal threshold under cue combination depends on congruency of visual and vestibular tuning for $(A)$ MSTd (from Gu et al. 2008) and (B) VIP (from Chen et al. 2013a). Data are shown as scatter plots of the ratio of the threshold measured in the combined condition relative to the prediction for optimal cue integration (Eq. 1) versus the Congruency Index. Cyan symbols are used for "congruent" neurons; magenta symbols are used for "opposite" neurons; open black symbols mark "intermediate" neurons. Dashed horizontal lines indicate that threshold in the combined condition is equal to the prediction. Solid lines show type II linear regressions. Neuronal thresholds are also plotted as means \pm SE for opposite and congruent neurons (top panels)

"congruency" was quantified using a "Congruency" index that varied from +1 for cells with congruent multisensory integration to -1 for cells with opposite multisensory integration.

Gu et al. (2008) (see also Gu et al. 2014) showed that congruent and opposite MSTd neurons play different roles in heading perception. As illustrated in Figure 6A, the neuronal threshold of congruent MSTd neurons was lowest in the combined condition and remarkably similar to the prediction from optimal cue integration models (Eq. 1; Fig. 6A, top; compare green and orange bars for the congruent cell panel), confirming that these cells increased their ability to discriminate small variations in heading direction when both cues were present. This finding suggests that congruent cells in MSTd satisfy one major prediction of optimal cue integration theory (Eq. 1). Fetsch et al. (2011) further showed that congruent MSTd neurons also satisfy the second prediction of opti- mal cue integration theory (Eq. 2). In contrast, opposite cells became less sensitive during combined stimulation (Fig. 6A, top; green bar for the opposite cell panel). In fact, there was a significant correlation between how well multisensory thresholds of MSTd neurons followed the predictions of optimal cue integration and the congruency index for those neurons (Fig. 6A, bottom panel). Remarkably, very similar results also characterize multisensory neurons in VIP (Fig. 6B; Chen et al. 2013a). The properties of FEF and VPS multisensory neurons during heading discrimination have not yet been examined.

\section{CONCLUSION}

Much progress has been made in recent years to understand the multisensory properties of heading discrimination in the parietal cortex of macaques, although these responses appear to remain egocentric (Fetsch et al. 2007; Chen et al. 2013b,c). The focus of this work has been primarily to derive a mechanistic understanding of how neural circuits give rise to multisensory perception in the context of probabilistic, statistical decision theory and the analysis of ideal observers. As summarized by Fetsch et al. (2013), this strategy has been based on linking neural responses with psychophysical performance in behaving animals, combined with computational modeling that has allowed comparisons with normative predictions.

Much work remains to be done to determine whether and how this multisensory circuit contributes to navigation and how egocentric heading signals interact with the allocentric representations of head direction, grid, and place cells in the medial temporal hippocampal networks. Evidence is rapidly mounting that multisensory interactions are more fundamental to these allocentric neural representations than previously thought (Ravassard et al. 2013). Hence, the quest to untangle and exploit the normative rules and principles of multisensory processing will be vital for understanding decision-making in the intersection of sensation, action, and experience.

\section{ACKNOWLEDGMENTS}

Experiments were supported by NIH EY017866 and DC007620. We thank Kalpana Dokka, Aihua Chen, Kaushik Lakshminarasimhan, and Reuben Fan for their assistance with figures and Michael Shinder for assistance with references.

\section{REFERENCES}

Alais D, Burr D. 2004. The ventriloquist effect results from nearoptimal bimodal integration. Curr Biol 14: 257-262.

Angelaki DE, Cullen KE. 2008. Vestibular system: The many facets of a multimodal sense. Annu Rev Neurosci 31: 125150.

Angelaki DE, Gu Y, DeAngelis GC. 2009. Multisensory integration: Psychophysics, neurophysiology, and computation. Curr Opin Neurobiol 19: 452-458.

Angelaki DE, Gu Y, Deangelis GC. 2011. Visual and vestibular cue integration for heading perception in extrastriate visual cortex. J Physiol 589: 825-833. 
Banks MS, Ehrlich SM, Backus BT, Crowell JA. 1996. Estimating heading during real and simulated eye movements. Vision Res 36: 431-443.

Barry C, Burgess N. 2014. Neural mechanisms of self-location. Curr Biol 24: R330-R339.

Berthoz A, Pavard B, Young LR. 1975. Perception of linear horizontal self-motion induced by peripheral vision (linearvection) basic characteristics and visual-vestibular interactions. Exp Brain Res 23: 471-489.

Brandt T, Dichgans J, Koenig E. 1972. Perception of self-rotation (circular vection) induced by optokinetic stimuli. Pflugers Arch 332 (Suppl 332): R398.

Bremmer F, Ilg UJ, Thiele A, Distler C, Hoffmann KP. 1997. Eye position effects in monkey cortex. I. Visual and pursuitrelated activity in extrastriate areas MT and MST. $J$ Neurophysiol 77: 944-961.

Bremmer F, Kubischik M, Pekel M, Lappe M, Hoffmann KP. 1999. Linear vestibular self-motion signals in monkey medial superior temporal area. Ann NY Acad Sci 871: 272-281.

Bremmer F, Duhamel JR, Ben Hamed S, Graf W. 2002. Heading encoding in the macaque ventral intraparietal area (VIP). Eur $J$ Neurosci 16: 1554-1568.

Britten KH. 2008. Mechanisms of self-motion perception. Annu Rev Neurosci 31: 389-410.

Burge J, Girshick AR, Banks MS. 2010. Visual-haptic adaptation is determined by relative reliability. $J$ Neurosci 30: 7714-7721.

Butler JS, Smith ST, Campos JL, Bülthoff HH. 2010. Bayesian integration of visual and vestibular signals for heading. $J$ Vis 10: 23 .

Butler JS, Campos JL, Bülthoff HH. 2015. Optimal visualvestibular integration under conditions of conflicting intersensory motion profiles. Exp Brain Res 233: $587-$ 597.

Chen A, DeAngelis GC, Angelaki DE. 2010. Macaque parietoinsular vestibular cortex: Responses to self-motion and optic flow. J Neurosci 30: 3022-3042.

Chen A, DeAngelis GC, Angelaki DE. 2011a. A comparison of vestibular spatiotemporal tuning in macaque parietoinsular vestibular cortex, ventral intraparietal area, and medial superior temporal area. J Neurosci 31: 3082-3094.

Chen A, DeAngelis GC, Angelaki DE. 2011b. Representation of vestibular and visual cues to self-motion in ventral intraparietal cortex. J Neurosci 31: 12036-12052.

Chen A, DeAngelis GC, Angelaki DE. 2011c. Convergence of vestibular and visual self-motion signals in an area of the posterior sylvian fissure. $J$ Neurosci 31: 11617-11627.

Chen A, Deangelis GC, Angelaki DE. 2013a. Functional specializations of the ventral intraparietal area for multisensory heading discrimination. J Neurosci 33: 3567-3581.

Chen X, Deangelis GC, Angelaki DE. 2013b. Diverse spatial reference frames of vestibular signals in parietal cortex. $\mathrm{Neu}$ ron 80: 1310-1321.

Chen X, DeAngelis GC, Angelaki DE. 2013c. Eye-centered representation of optic flow tuning in the ventral intraparietal area. J Neurosci 33: 18574-18582.

Chowdhury SA, Takahashi K, DeAngelis GC, Angelaki DE. 2009. Does the middle temporal area carry vestibular signals related to self-motion? J Neurosci 29: 12020-12030.

Crowell JA, Andersen RA. 2001. Pursuit compensation during self-motion. Perception 30: 1465-1488.

Crowell JA, Banks MS, Shenoy KV, Andersen RA. 1998. Visual self-motion perception during head turns. Nat Neurosci 1: $732-737$.

DeAngelis GC, Angelaki DE. 2012. Visual-vestibular integration for self-motion perception. In The neural bases of multisensory processes (ed. Murray MM, Wallace MT), Chapter 31. CRC Press, Boca Raton, FL.

de Winkel KN, Weesie J, Werkhoven PJ, Groen EL. 2010. Integration of visual and inertial cues in perceived heading of self-motion. J Vis 10: 1 .

de Winkel KN, Soyka F, Barnett-Cowan M, Bülthoff HH, Groen EL, Werkhoven PJ. 2013. Integration of visual and inertial cues in the perception of angular self-motion. Exp Brain Res 231: 209-218.

Dichgans J, Brandt T. 1978. Visual-vestibular interaction: Effects on self-motion perception and postural control. In Handbook of sensory physiology (ed. Held R, Leibowitz HW, Teuber HL), pp. 756-804. Springer, Berlin.

Dokka K, MacNeilage PR, DeAngelis GC, Angelaki DE. 2015. Multisensory self-motion compensation during object trajectory judgments. Cereb Cortex 25: 619-630.

Drugowitsch J, DeAngelis GC, Klier EM, Angelaki DE, Pouget A. 2014. Optimal multisensory decision-making in a reactiontime task. Elife 3: doi: 10.7554/eLife.03005.

Duffy CJ. 1998. MST neurons respond to optic flow and translational movement. J Neurophysiol 80: 1816-1827.

Duffy CJ, Wurtz RH. 1995. Response of monkey MST neurons to optic flow stimuli with shifted centers of motion. J Neurosci 15: 5192-5208.

Ernst MO, Banks MS. 2002. Humans integrate visual and haptic information in a statistically optimal fashion. Nature 415: $429-433$

Ernst MO, Di Luca M. 2011. Multisensory perception: From integration to remapping. In Sensory cue integration (ed. Trommershauser J, Kording K, Landy MS), pp. 224-250. Oxford University Press, Oxford.

Etienne AS, Maurer R, Saucy F, Teroni E. 1986. Short-distance homing in the golden hamster after a passive outward journey. Anim Behav 34: 696-715.

Fajen BR, Matthis JS. 2013. Visual and non-visual contributions to the perception of object motion during self-motion. PLoS One 8: e55446.

Fetsch CR, Wang S, Gu Y, Deangelis GC, Angelaki DE. 2007. Spatial reference frames of visual, vestibular, and multimodal heading signals in the dorsal subdivision of the medial superior temporal area. J Neurosci 27: 700-712.

Fetsch CR, Turner AH, DeAngelis GC, Angelaki DE. 2009. Dynamic reweighting of visual and vestibular cues during self-motion perception. $J$ Neurosci 29: 15601-15612.

Fetsch CR, DeAngelis GC, Angelaki DE. 2010. Visual-vestibular cue integration for heading perception: Applications of optimal cue integration theory. Eur J Neurosci 31: 17211729.

Fetsch CR, Pouget A, DeAngelis GC, Angelaki DE. 2011. Neural correlates of reliability-based cue weighting during multisensory integration. Nat Neurosci 15: 146-154.

Fetsch CR, DeAngelis GC, Angelaki DE. 2013. Bridging the gap between theories of sensory cue integration and the physiology of multisensory neurons. Nat Rev Neurosci 14: 429442.

Geva-Sagiv M, Las L, Yovel Y, Ulanovsky N. 2015. Spatial cognition in bats and rats: From sensory acquisition to multiscale maps and navigation. Nat Rev Neurosci 16: 94-108.

Gibson JJ. 1950. The perception of the visual world. HoughtonMifflin, Boston, MA.

Gori M, Del Viva M, Sandini G, Burr DC. 2008. Young children do not integrate visual and haptic form information. Curr Biol 18: $694-698$.

Gori M, Sandini G, Martinoli C, Burr D. 2010. Poor haptic orientation discrimination in nonsighted children may reflect disruption of cross-sensory calibration. Curr Biol 20: 223-225.

Gori M, Mazzilli G, Sandini G, Burr D. 2011a. Cross-sensory facilitation reveals neural interactions between visual and tactile motion in humans. Front Psychol 2: 55.

Gori M, Sciutti A, Burr D, Sandini G. 2011b. Direct and indirect haptic calibration of visual size judgments. PLoS One 6: e25599.

Gori M, Giuliana L, Sandini G, Burr D. 2012a. Visual size perception and haptic calibration during development. Dev Sci 15: 854-862.

Gori M, Sandini G, Burr D. 2012b. Development of visuo-auditory integration in space and time. Front Integr Neurosci 6: 77.

Gori M, Squeri V, Sciutti A, Masia L, Sandini G, Konczak J. 2012c. Motor commands in children interfere with their haptic perception of objects. Exp Brain Res 223: 149-157. 
Grigo A, Lappe M. 1999. Dynamical use of different sources of information in heading judgments from retinal flow. J Opt Soc Am A Opt Image Sci Vis 16: 2079-2091.

Gu Y, Watkins PV, Angelaki DE, DeAngelis GC. 2006. Visual and nonvisual contributions to three-dimensional heading selectivity in the medial superior temporal area. $J$ Neurosci 26: $73-85$.

Gu Y, DeAngelis GC, Angelaki DE. 2007. A functional link between area MSTd and heading perception based on vestibular signals. Nat Neurosci 10: 1038-1047.

Gu Y, Angelaki DE, DeAngelis GC. 2008. Neural correlates of multisensory cue integration in macaque MSTd. Nat Neurosci 11: $1201-1210$.

Gu Y, Angelaki DE, DeAngelis GC. 2014. Contribution of correlated noise and selective decoding to choice probability measurements in extrastriate visual cortex. Elife 3: doi: 10.7554/eLife.02670.

Haith A, Jackson C, Miall C, Vijayakumar S. 2008. Interactions between sensory and motor components of adaptation predicted by a Bayesian model. In Workshop on advances in computational motor control (ACMC 2008).

Hartley T, Lever C, Burgess N, O'Keefe J. 2013. Space in the brain: How the hippocampal formation supports spatial cognition. Philos Trans R Soc Lond B Biol Sci 369: 20120510.

Hillis JM, Watt SJ, Landy MS, Banks MS. 2004. Slant from texture and disparity cues: Optimal cue combination. $J$ Vis 4: 967-992.

Knierim JJ, Zhang K. 2012. Attractor dynamics of spatially correlated neural activity in the limbic system. Annu Rev Neurosci 35: 267-285.

Knill DC, Pouget A. 2004. The Bayesian brain: The role of uncertainty in neural coding and computation. Trends Neurosci 27: 712-719.

Knill DC, Saunders JA. 2003. Do humans optimally integrate stereo and texture information for judgments of surface slant? Vision Res 43: 2539-2558.

Li L, Warren WH Jr. 2000. Perception of heading during rotation: Sufficiency of dense motion parallax and reference objects. Vision Res 40: 3873-3894.

Li L, Warren WH Jr. 2002. Retinal flow is sufficient for steering during observer rotation. Psychol Sci 13: 485-491.

Li L, Warren WH Jr. 2004. Path perception during rotation: Influence of instructions, depth range, and dot density. Vision Res 44: 1879-1889.

Mach E. 1875. Grundlinien der Lehre von den Bewegungsempfindungen. W. Engelmann, Leipzig.

Maciokas JB, Britten KH. 2010. Extrastriate area MST and parietal area VIP similarly represent forward headings. J Neurophysiol 104: 239-247.

Mazzoni P, Krakauer JW. 2006. An implicit plan overrides an explicit strategy during visuomotor adaptation. $J$ Neurosci $\mathbf{2 6}$ : $3642-3645$.

Mittelstaedt M-L, Mittelstaedt H. 1980. Homing by path integration in a mammal. Naturwissenschaften 67: 566-567.

Moser EI, Moser MB, Roudi Y. 2013. Network mechanisms of grid cells. Philos Trans R Soc Lond B Biol Sci 369: 20120511.

Nardini M, Jones P, Bedford R, Braddick O. 2008. Development of cue integration in human navigation. Curr Biol 18: 689-693.

Page WK, Duffy CJ. 2003. Heading representation in MST: Sensory interactions and population encoding. JNeurophysiol 89: 1994-2013.

Ravassard P, Kees A, Willers B, Ho D, Aharoni D, Cushman J, Aghajan ZM, Mehta MR. 2013. Multi-sensory control of hippocampal spatiotemporal selectivity. Science 340: 13421346.
Royden CS. 1994. Analysis of misperceived observer motion during simulated eye rotations. Vision Res 34: 3215-3222.

Royden CS, Hildreth EC. 1996. Human heading judgments in the presence of moving objects. Percept Psychophys 58: 836-856.

Royden CS, Banks MS, Crowell JA. 1992. The perception of heading during eye movements. Nature 360: 583-585.

Royden CS, Crowell JA, Banks MS. 1994. Estimating heading during eye movements. Vision Res 34: 3197-3214.

Royden CS, Cahill JM, Conti DM. 2006. Factors affecting curved versus straight path heading perception. Percept Psychophys 68: 184-193.

Saunders JA, Warren WH. 1996. Perceived heading biased by a moving object: Effects of disparity and object position. Invest Ophthalmol Vis Sci 37: S454.

Schlack A, Hoffmann KP, Bremmer F. 2002. Interaction of linear vestibular and visual stimulation in the macaque ventral intraparietal area (VIP). Eur J Neurosci 16: 1877-1886.

Simani MC, McGuire LM, Sabes PN. 2007. Visual-shift adaptation is composed of separable sensory and task-dependent effects. J Neurophysiol 98: 2827-2841.

Stein BE, Rowland BA. 2011. Organization and plasticity in multisensory integration: Early and late experience affects its governing principles. Prog Brain Res 191: 145-163.

Stone LS, Perrone JA. 1997. Human heading estimation during visually simulated curvilinear motion. Vision Res 37: $573-$ 590.

Stuchlik A, Bures J. 2002. Relative contribution of allothetic and idiothetic navigation to place avoidance on stable and rotating arenas in darkness. Behav Brain Res 128: 179-188.

Sunkara A, DeAngelis GC, Angelaki DE. 2015. Role of visual and non-visual cues in constructing a rotation-invariant representation of heading in parietal cortex. Elife 4: doi: 10.7554/eLife.04693.

Tanaka M, Weber H, Creutzfeldt OD. 1986. Visual properties and spatial distribution of neurones in the visual association area on the prelunate gyrus of the awake monkey. Exp Brain Res 65: $11-37$.

Taylor JA, Ivry RB. 2011. Flexible cognitive strategies during motor learning. PLoS Comput Biol 7: e1001096.

van den Berg AV, Brenner E. 1994. Humans combine the optic flow with static depth cues for robust perception of heading. Vision Res 34: 2153-2167.

Warren WH Jr. 2003. Optic flow. In The visual neurosciences (ed. Chalupa LM, Werner JS), pp. 1247-1259. MIT Press, Cambridge, MA.

Warren WH Jr, Hannon DJ. 1990. Eye movements and optical flow. J Opt Soc Am A 7: 160-169.

Warren WH Jr, Saunders JA. 1995. Perceiving heading in the presence of moving objects. Perception 24: 315-331.

Warren WH Jr, Morris MW, Kalish M. 1988. Perception of translational heading from optical flow. J Exp Psychol Hum Percept Perform 14: 646-660.

Yang Y, Liu S, Chowdhury SA, DeAngelis GC, Angelaki DE. 2011. Binocular disparity tuning and visual-vestibular congruency of multisensory neurons in macaque parietal cortex. J Neurosci 31: 17905-17916.

Zaidel A, Turner AH, Angelaki DE. 2011. Multisensory calibration is independent of cue reliability. J Neurosci 31: 1394913962.

Zaidel A, Ma WJ, Angelaki DE. 2013. Supervised calibration relies on the multisensory percept. Neuron 80: 1544-1557.

Zhang T, Heuer HW, Britten KH. 2004. Parietal area VIP neuronal responses to heading stimuli are encoded in head-centered coordinates. Neuron 42: 993-1001. 


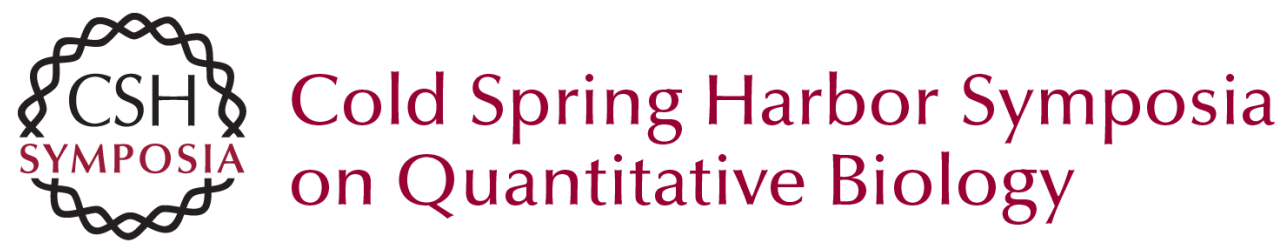

\section{How Optic Flow and Inertial Cues Improve Motion Perception}

Dora E. Angelaki

Cold Spring Harb Symp Quant Biol 2014 79: 141-148

Access the most recent version at doi:10.1101/sqb.2014.79.024638

References This article cites 89 articles, 18 of which can be accessed free at: http://symposium.cshlp.org/content/79/141.full.html\#ref-list-1

\section{License}

Email Alerting Receive free email alerts when new articles cite this article - sign up in Service the box at the top right corner of the article or click here. 